Volume 7

Issue 3 May

Article 8

May 1980

\title{
Changing Physician Ideologies on the Care of the Dying: Themes and Possible Explanations
}

John MacDougall

University of Lowell

Follow this and additional works at: https://scholarworks.wmich.edu/jssw

Part of the Clinical and Medical Social Work Commons, Palliative Care Commons, and the Social Work Commons

\section{Recommended Citation}

MacDougall, John (1980) "Changing Physician Ideologies on the Care of the Dying: Themes and Possible Explanations," The Journal of Sociology \& Social Welfare: Vol. 7 : Iss. 3 , Article 8.

Available at: https://scholarworks.wmich.edu/jssw/vol7/iss3/8 
CHANGING PHYSICIAN IDEOLOGIES ON THE CARE OF THE DYING: THEMES AND POSSIBLE EXPLANATIONS

\author{
John MacDougall, University of Lowell *
}

An analysis of changing physician ideologies regarding the care of elderly dying patients, as expressed in technical journals read by American physicians. Markedly more titles concerning terminal care are found in Index Medicus in 196878 than in 1960-67. In one journal, physicians are only after 1964 unged to tell patients openly about their condition and after 1969, to improve cooperation within professional teams. Two explanations of these data are tentatively explored: 1) a Parsonian explanation, whereby medical ideologies reflect professional autonomy and the influence of internalized moral norms; 2) a Marxist explanation, whereby medical ideologies reflect physicians' transformation from independent intrepreneurs into technological/ bureaucratic agents of the state under monopoly capitalism. Data are summarized which fail to support the Parsonian explanation, but which do support the Marxist explanation concerning the growth in salary payment of doctors and the government's role in terminal care.

\title{
I. INTRODUCTION
}

This paper has two goals; first, to describe how the American medical profession has in recent years publicly stated its norms about the care of the elderly dying; and second, to explore in a preliminary way possible reasons for changes in these norms. 1

\footnotetext{
*Revised version of paper given at the annual meetings of the Society for the Study of Social Problems, Boston, August, 1979. Many thanks are due to Phil Brown, Johannes Fabian, Renee Fox, Liz Markson, Al Plough, Susan Reverby and Irving Zola for their helpful comments, and to Sandra Abbott, Jill Clayton, Collette Destours, Carol Montgomery and Kathy Mull for research and clerical assistance.
}

1. We only focus on the care of the aged dying. In the case of children, youths or relatively youthful adults who are dying, a different set of values are involved. (Parsons and Lidz, 1967). 
The analysis in this paper is necessarily tentative and preliminary. There is to this author's knowledge no systematic analysis of changes in institutionalized medical ideologies regarding terminal care. Furthermore, there are few careful accounts of changing medical ideologies on any topic. Yet the topic of physician ideo1ogies is 1mportant in understanding health-care in contemporary America. For physicians play a vital role not only in shaping everyday actions and expectations, but also in influencing national and regional resource allocations and decision-making procedures in health care. (MacDougal1 and Rawnsley, 1978).

An ideology may be defined as a set of interrelated cognitive perceptions and moral prescriptions/prohibitions pertaining to some social group. (Wallace, 1956; Waterman and Waitzkin, unpublished). In this paper, our main concern is with the moral aspect of physicians' ideologies. The medical profession sees its work as based on modern science, yet always directed to the solution of practical problems. ${ }^{2}$

In the next section of this paper, we describe some of the changes in physicians' ideologies since the nineteen-fifties, expecially the greater salience of the whole issue of terminal care after 1967 and the increased emphasis in the later period on professional teamwork and on open discussions with patients. In Section III we briefly present three important perspectives in medical sociology. We then briefly review some data that will help us choose between those perspectives in explaining changes in medical ideologies after 1967. In Sections III and IV we suggest some ways in which a more rigorous analysis might be conducted.

\section{THE NATURE OF IDEOLOGICAL CHANGES}

An appropriate place to seek evidence of official medical ideologies is in professional medical journals. This is because the medical profession claims to be guided by general norms, scientific knowledge and practical expertise, and information on those matters is supposed to be public. Moreover, knowledge, experience and environmental conditions are always changing, and the medical profession is supposed to be adaptable and up-to-date, so doctors are expected to keep themselves informed about the latest scientific, practical and ethical developments.

2. Something may be learned about medical ideologies from the numerous studies of physicians' attitudes to death and dying. (e.g., Crane, 1975; Okin, 1961; Schulz and Aderman, 1976). However, such attitudes are not the same as ideologies, as we have defined the term, and most attitude studies fail to deal with the societal setting or with possible secular changes in attitudes. 
Let us now consider evidence to be found in specific medical journals.

\section{A. Numbers of Journal Articles}

First, let us consider the frequency of entries on terminal care in Cumulated Index Medicus each year between 1960 and 1978. We have counted numbers of articles, editorials and letters on non-technical aspects of physicians' roles in the care of the aged dying. ${ }^{3}$ These figures--in TABLE 1-- show that while the number of entries fluctuated quite sharply from year to year, the number was consistently higher after 1966 than before it. 4

\section{TABLE 1}

Annual numbers of entries on the care of the dying listed in Cumulated Index Medicus, 1960-77

YEAR NUMBER OF ENTRIES

YEAR NUMBER OF ENTRIES

1960

1961

1962

1963

1964

1965

1966

1967

1968

1969

$\begin{array}{rr}6 & 1970 \\ 4 & 1971 \\ 4 & 1972 \\ 5 & 1973 \\ 9 & 1974 \\ 10 & 1975 \\ 7 & 1976 \\ 16 & 1977 \\ 32 \star & 1978\end{array}$

18

26

$1972 \quad 20$

$1973 \quad 29$

$1974-22$

14

29

12

*Includes ten entries in Medical Times, which is an exceptionally large number of entries in one medical journal in one year.

3. Further details on methods of data-collection and analysis are available from the author.

4. Year-to-year changes in numbers of articles in Index Medicus partly relect specific short-run developments like well-known lawsuits or new techniques. These changes are not considered in this paper. 


\section{B. Themes in Particular Medical Iournals}

To provide a qualitative description of changing medical ideologies, material in one particular medical journal has been subjected to content analysis. This journal is the Journal of Chronic Diseases ( JCD for short), a journal of considerable stature in the profession, whose contributors and editors represent specialties closely involved in the care of dying patients. The JCD, since its establishment in 1955, has demonstrated a keen awareness of ethical and policy issues in patient care, and a willingness to editorialize on those issues. Thus statements in the JCD may be taken as quite representative of the views of influential physicians and of major centers of medical teaching and research on a wide range of terminal-care issues. 5

TABLE 2 shows that in no year was there a great number of statements. However, there were markedly more statements in 1969 and following four years, than before 1969 .

TABLE 2

Annual numbers of statements on the care of the dying in the Journal of Chronic Diseases, 1955-77

YEAR NUMBER OF STATEMENTS

1955

1956

1957

1958

1959

1960

1961

1962

1963

1964

1965

1966

\section{1}

0

0

3

0

0

0

0

$10 *$

6

0

0
YEAR NUMBER OF STATEMENTS

1967

1968

1969

1970

1971

1972

1973

1974

1975

1976

1977
0

0

7

6

5

0

10

0

0

0

1

*These statements were found in three articles or editorials. In all other years in which statements on the care of the dying were found, they were found in only one article or editorial.

5. Statements in the JCD were drawn from all articles, editorials and letters that had to do with the care of dying patients, or the care of sufferers from any chronic disease. 
The themes of these statements were to some extent different in the two sub-perfods 1955-64 and 1969-77. But there were also continuities between the two sub-periods. Let us consider the most common themes.

The patient and his/her family. Both before and after 1969 it was of ten emphasized that doctors should control the patient's pain and distress. For example, it was suggested in 1973 that:

the...objectives [of care for cancer patlents in whom there is still obvious residual tumor growth left, even following primary treatment] may be defined as attempting to alleviate his symptoms so that the remaining period of the patient's life will be as comfortable and functional as possible, so that in the final period of his life no man should feel in today's society that he has been cast out to die. (Iszak et al, 1973: 371;

cf. Hinton, 1964).

Another common point in the JCD is that physicians should pay closer attention to patients' emotional problems. In 1963, Dr. R. A. Senescu stated:

of particular importance in patients with acute emotional disturbance who may not have much time to live is the fact that ... the problem was [and clearly, in Dr. Senescu's opinion, should be] dealt with directly and entirely in terms of the patient's present emotional reaction.

(Senescu, 1963: 830; cf. Theologides, 1971).

Concerning the intractable problems of what the physician should tell the dying patient and how, writers in the JCD continually emphasized the need for sympathy in discussions with the patient. 6 However, there are marked changes over time in opinions as to how openly the doctor should tell the patient he/she is dying. On this matter, a change of opinion occurred before the usual transitional year 1969. In 1958, Dr. R. R. Newe11 recommended:

6. Okun (1961), commenting on his well-known study in the Journal of the AMA, felt that doctors should not tell patients about their condition. In the New England Journal of Medicine of 1957, the degradation of the patient by the modern slow method of dying is deplored. Yet it is never suggested that the problem might be alleviated by a frank discussion between doctor and patient (Life-in-Death, 1957). 
Don't try to tell [the patient] what you know he cannot accept... Don't tell him your diagnosis until you are sure... Manage to see mother (or wife, or husband) alone and quietly for an hour without the patient's knowing of it. Lie to the patient, if you must, for his own good... Leave the patient always one straw of hope to cling to. (Newel1, 1958: 56-57).

Earlier in the article Dr. Newell said:

At the very least you can ask the patient to look at the rapid advances of medical science and to hope that the cure for his disease is on the verge of discovery and will possibly be announced next week. (Newe11, 1958: 56).

But in an editorial in 1964, Dr. John Hinton urged physicians to "speak more openly to dying patients and their families" and to have a "quiet unhurried discussion with the patient". (Hinton, 1964: 203). In 1969 Dr. Louis Lasagna went further. Like Dr. Newell in 1958, Dr. Lasagna advocated leaving some hope in the patient's mind. But in all other respects, Dr. Lasagna disagreed with Dr. Newell:

While the patient has a right live, he also has the right to die... In any case, the "truth" should always be told in a sympathetic and considerate manner, holding out at least some hope of the doctor's ability to modify certain manifestations of the disease, and to ease the pain or other distress.

Lying to a patient about a serious illness is usually bad business, if for no other reason than that the patient will inevitably receive cues and clues about the truth from the environment. (Lasagna, 1969: 67).

Relationships with colleagues. In the entire period under discussion, articles and editorials in the JCD advocated a team approach to terminal care. However, different specific aspects of teamwork were mentioned in 1955-64 and in 1969-73. In the former period, teams were discussed only in general terms. (e.g., Conner et al, 1955). But in the nineteen-seventies, the contributions of specific types of colleagues are mentioned--in positive tones. These include priests and primary-care physicians. (Iszak et al, 1973; Theologides, 1971).

Moreover, the main problem in relationships with colleagues that is mentioned in the nineteen-fifties and early nineteen-sixties is group morale. (Conner et al, 1955). But in the late nineteen-sixties and nineteen-seventies, cooperation and communication with other physicians, nurses and social workers were seen as seriously deficient. (Iszak et al, 1973). 
Thus in the late nineteen-sixties there emerged an emphasis on greater honesty in relationships with patients, and on closer collaboration with specific groups of professionals in the care of the dying.

III. EXPLANATIONS OF CHANGING IDEOLOGIES--A PRELIMINARY ANALYSIS

Parsons, Marx, and Friedson: General Models

Before attempting to explain the data just presented, let us summarize three sociological perspectives on the medical profession that are influential yet of ten incompatible.

The first is the Parsonian perspective, according to which doctors are influenced above all by their high moral and scientific standards, and have much autonomous control over the normative, scientific and technological aspects of their work.

Physicians, it is argued, play an increasing1y important role in propagating and implementing the instrumental-activist values of American society, especially as they relate to human life. Certain aspects and stages of life--of which death and dying are notable examples--cause much pain and uncertainty, owing to the advances of biomedical technology and to the secularization of American culture. Doctors are then called upon to make authoritative factual and normative statements, which are the functional equivalent of religious creeds and rules.?

Regarding the care of the dying, Parsons and his associates claim that physicians are influenced by both the public's demand for certainty and their own guilt at the prospect of "failure" when a patient dies. Because of these pressures, physicians seek first, to reinterpret the ancient Judeo-Christian value of the dignity and importance of divinely-given human life, in a new, relativistic form; and second, to formulate technical and ethical principles that justify the treatment of each individual

7. Cf. Parsons' suggestion that health-care institutions are increasingly interested in mental illness, as somatic diseases come to be "conquered", and as greater responsibility is placed on the individual in a highly urbanized society (Parsons, 1972: 121). Parsons presumably feels that psychological problems pose very important challenges in terminal care. 
patient. (Parsons, 1972; Parsons and Lidz, 1967: Parsons et al., 1973; Merton et a1., 1957). ${ }^{8}$

The second perspective examined is the Marxist one, which sees the medical profession as gradually turning into agents of monopoly capital and its state apparatus. This is a complex dialectical process, but its main elements are the following.

The health-care industry is seen by Marxists as having in the past two decades undergone a major change in its mode of production, from a petty-commodity mode to a large-scale, hightechnology mode. Further, various significant social and political changes have taken place in recent years, largely to facilitate the change in the mode of production. Most important, medicine has developed tighter links with profit making manufacturers of drugs, supplies and equipment, more rigorous controls over subordinate health care workers, and closer ties with third-party payers (so as to ensure physicians' solvency and continuous expansion of health-care institutions such as hospitals). Doctors and the organizations where they work have also recently taken a closer interest in state policy, and obtained larger amounts of state funds. Doctors have done this, both to promote the above-mentioned relationships with manufacturers, subordinate workers, etc., and to legitimate the general status quo in health-care, which is characterized by free-enterprise providers and a medical monopoly over diagnosis and treatment.

However, organizations providing and financing health-care have been hampered in their ability to fully introduce these socio-political changes by two external forces. The first force is the growing concern of monopoly capital as a whole, with both the escalating cost of health-care for its workers and the preservation of private enterprise in health-care. The second force comes from workers and consumers. They, like employers, are becoming more and more angry at the high cost of health-care. Workers and consumers are also getting angry at the inhumanity and limited efficacy of that care, and at their inability to influence health-care institutions. These two forces mean that there are many "eddies" running counter to the main "stream" that was described in the previous paragraph. In particular, Marxists predict that medical ideologies will display an acceptance of large-scale, high-technology settings of care, but will

8. In particular, Parsons and Lidz (1967: 138) claim that physicians are expected to do everything possible to prevent deaths from being "premature" or "avoidable". 
also seek to legitimate the continuing control of those settings by physicians (as an "updated" version of the petty-commodity mode) (McKinlay, unpublished; Navarro, 1976, 1978; Rodberg and Stevenson, 1977).9

A third influential perspective on the medical profession is that of Eliot Freidson. Freidson makes two main points. First, physicians' behavior is influenced more by their immediate work settings and their operating norms than by the general norms and scientific knowledge they have internalized. Second, the typical work setting of contemporary doctors is, according to Freidson, one where doctors have been granted autonomy by some elite in the society. When we apply these two postulates to the analysis of ideological change in medicine, we encounter serfous problems: unlike the Parsonian and Marxist approaches, Friedson's is primarily static; and it is unclear how the medical profession is granted autonomy by the state (McKinlay, 1977). Still, Freidson would probably argue that changes in the microstructures of work settings, and in the operative norms of those settings, lead to changes in the perceived crucial interests which doctors feel they must defend, and hence to changes in the nature of their ideological statements. Unlike Marxists, Freidson believes there has been no major reduction in physicians' autonomy since about 1960 . Freidson would also presumably argue that doctors still see their ideological task as the defense of their autonomy. (Freidson, 1970a, 1970b, 1975).10

9. Rodberg and Stevenson (1977) term the current mode of production in health-care the capitalist mode. This is a misnomer, since the petty-commodity mode is also capitalist. At present, monopoly capital appears to be more anxious about health-care cost-containment and about general legitimation of the capitalist form of health-care, than about some of the other functions that health-care performs for monopoly capital, such as providing investment outlets (Rodberg and Stevenson, 1977). An additional cause of worker/consumer discontent that is somewhat relevant is capital's increasingly salient role in causing workplace hazards and pollution. These popular sentiments appear to have less impact on demands regarding terminal care than do worker/consumer anger over health-care services.

10. We should mention briefly the current popular view that physicians are the primary cause of the expansion of biomedical technology and of medical definitions of social and personal problems (I1lich, 1976: cf. Navarro, 1976: 103-34). While exponents of this view disagree with Parsonians and with Freidson 
Parsons, Marx and Freidson: Empirical Indicators.

It is evident that Parsons and the Marxists offer highly complex explanations of trends in medical ideologies, and in the health-care system as a whole. If we try to test the two explanations, we will not find it easy to operationalize the major variables and the relationships between those variables. However, we suggest the following types of evidence are the most important. We will focus on the various independent variables (not the dependent variable of medical ideologies of terminal care).

For a Parsonian, the first type of data concerns research and development of major new technologies affecting doctors' power over death. Especially important is research and development that takes place in medical schools and hospitals, rather than in private industry or government agencies, since the former stems most directly from the knowledge and values of physicians themselves. Second, evidence would be sought of changes in the public's general attitudes towards scientific and rational approaches to human problems--which would indicate the types of broad cultural pressures to which physicians have to respond in advancing medical technologies. Third, the general normative statements and practices of the medical profession would receive attention, regarding such issues as whether doctors have the right to define and manage all aspects of health, ethical standards for health-care workers and patients, and the rights of different social strata to health services (cf. Parsons et al., 1973: 20-21). Finally, these statements would be linked to changing public attitudes on these matters, and to demands by legitimate public leaders (clergypersons, lawyers, scientists, etc.) that the medical profession clarify or change its stance in these areas. We should add that data on all these four topics should reflect not only formal organizational behaviour and official statements, but also informal behaviour and unofficial opinions.

on many points, they do agree on the basic claim that the medical profession is autonomous. The Parsonian perspective is also unable to predict at least one trend in the dependent variable, namely the growing emphasis in the JCD on doctors' collaboration with their "team-mates". Parsonians--who are much more explicit about terminal-care ideologies than Marxists--claim that doctors still claim exclusive authority over every patient's treatment (Parsons et al., 1973). 
A Marxist might document the changing mode of production of health care by describing the growing use in different care settings of expensive high technology equipment such as CAT scanners. Regarding the accompanying social and political changes we have discussed, the choice of indicators is relatively easy. For instance, we need to know the changing proportion of terminal care actually given in hospitals as compared with patients' homes. (Nursing homes are an important setting of terminal care. They should probably be classified as employing a petty-commodity mode of production in most cases). In addition, we would need to know whether leading medical schools and large hospitals are increasingly often represented on federal policy-making committees, and on drug-company boards of directors. We would also look at the frequency with which leading business associations, labor unions, and consumer groups demand that health-care cost inflation be curtailed.

However, it is not easy to show the relative severity of the various contradictions that accompany the general trend. Possible evidence for contradictions includes the changing volume and content of public self-justifications by leading hospitals, insurance companies, etc.; and the extent to which physicians engage in public debates on major health-care issues (when collecting these data, we should also examine the protagonists' specialties and institutional affiliations).

As we have indicated, Freidson (unlike both Parsons and the Marxists) has not articulated an explicit model of ideological change in medicine. But he would probably look especially at developments such as the changing use of attending hospital physicians as opposed to office-based solo practitioners, and at trends in the complexity and size of the "teams" that actually care for patients. Regarding normative changes at the workplace, Freidson would be particularly interested in the changing extent to which doctors were expected to respond to the needs--even orders--of the team as a whole, of the organizations where they worked, and of their professional associations.

We should now move on to some empirical data. Before doing so, we should mention that we present no data to test the usefulness of Freidson's perspective. We do this for two reasons. First, Freidson does not have a systematic theory of ideological change. Second, some of the general causal factors mentioned by Freidson are similar to some of those mentioned by the Parsonians, while others of Freidson's factors overlap with the Marxists'. Accordingly, in a preliminary analysis like this one, where we cannot be sure about even the hypothetical relationships between 
the variables, it is more appropriate to test two perspectives-the Marxist and the Parsonian--that are, roughly speaking, mutually exclusive.

We have only been able to collect readily-available published data that bear on our two perspectives. We have chosen data that unambiguously reflect either the Parsonian or the Marxist approach, but not both. Unfortunately, such data are too crude to permit an analysis of possible dialectic processes. In interpreting the various time-series presented below, we follow the elementary rule that if a change in an independent variable happened after a change in the dependent variable, that independent variable does not operate as a cause.

Evidence for a Parsonian Explanation.

If the Parsonian explanation of medical ideologies is correct, we should find that medical schools--which are among the main institutions for the socialization of professional norms--formally expressed a concern with the care of the dying before the profession as a whole. However, the evidence suggests that the nation's medical schools typically followed rather than led the general profession on terminal-care issues. According to Cumulated Index Medicus, it was not until 1970 that any medicaleducation journal mentioned the care of the dying, or any medical school offered formal courses on this topic. (Dickinson, 1976; Liston, 1973, 1975).

Another implication of the Parsonian perspective is that the most prestigious medical journals will be concerned with terminalcare issues, before "rank-and-file" medical journals. This, it is held, is because the leaders of the profession feel duty-bound to be the first physicians to seriously discuss and disseminate new knowledge and values. Yet in the very prestigious New England Journal of Medicine there was not (according to Cumulated Index Medicus) a single article, editorial or letter on terminal care until 1968, i.e., after the attainment of a generally-higher level of concern with the dying in the general medical literature. 11 Similarly, in the JCD normative themes usually changed

11. A detailed content analysis of statements on terminal care in the New England Journal of Medicine is undertaken in MacDougall and Ost, unpublished. 
only in $1969,,^{12}$ and the number of statements on terminal care only increased in $1969^{13}$ (see section II).

However, calls in the JCD for closer cooperation with colleagues, and for respect for the right to die, are consistent with the Parsonian view that in the sixties the medical profession took a more relativistic view of terminal-care ethics. But even granting this, we must still mention as evidence against the Parsonian perspective the fact that the new, more relativistic ethic was not expressed in the JCD until 1969, i.e., after interest in terminal care markedly escalated in less prestigious journals.

\section{Evidence for a Marxist Explanation}

One important indicator of the changing mode of production in health-care is the diffusion of complex biomedical technologies in hospitals. Russell (1976) has shown that between 1953 and 1974, the proportion of middle-sized hospitals possessing diagnostic radio-isotope equipment, electro-encephalograph machines, and cobalt therapy equipment--all techniques frequently used in the treatment of terminal diseases--have grown steadily, but without any sudden spurts. 14

Turning to the important socio-political concomitants of the changed mode of production, let us first examine the penetration of terminal-care settings by corporate capital. An indicator of this penetration is the extent to which terminalcare goods and services are bought from profit-making corporations. A rough estimate of such purchases can be made on the basis of Stevenson's (1976) data on corporate sales to the whole health-care system. In TABLE 3, we have selected those goods and services mentioned by Stevenson that are most frequently used in the treatment of dying patients. The figures show large absolute increases in corporate sales, but no growth in such

12. An exception is Hinton (1964).

13. This is particularly true if we bear in mind that in 1963, there were three articles on terminal care--exceptionally large numbermin the JCD.

14. The proportion of hospitals using radium and $x-r a y$ therapy facilities actually fell after the early 1960s, because those technologies became obsolete (Russell, 1976: 566). Russe1l's data on cobalt and radium therapy equipment only cover the period 1965-74. 


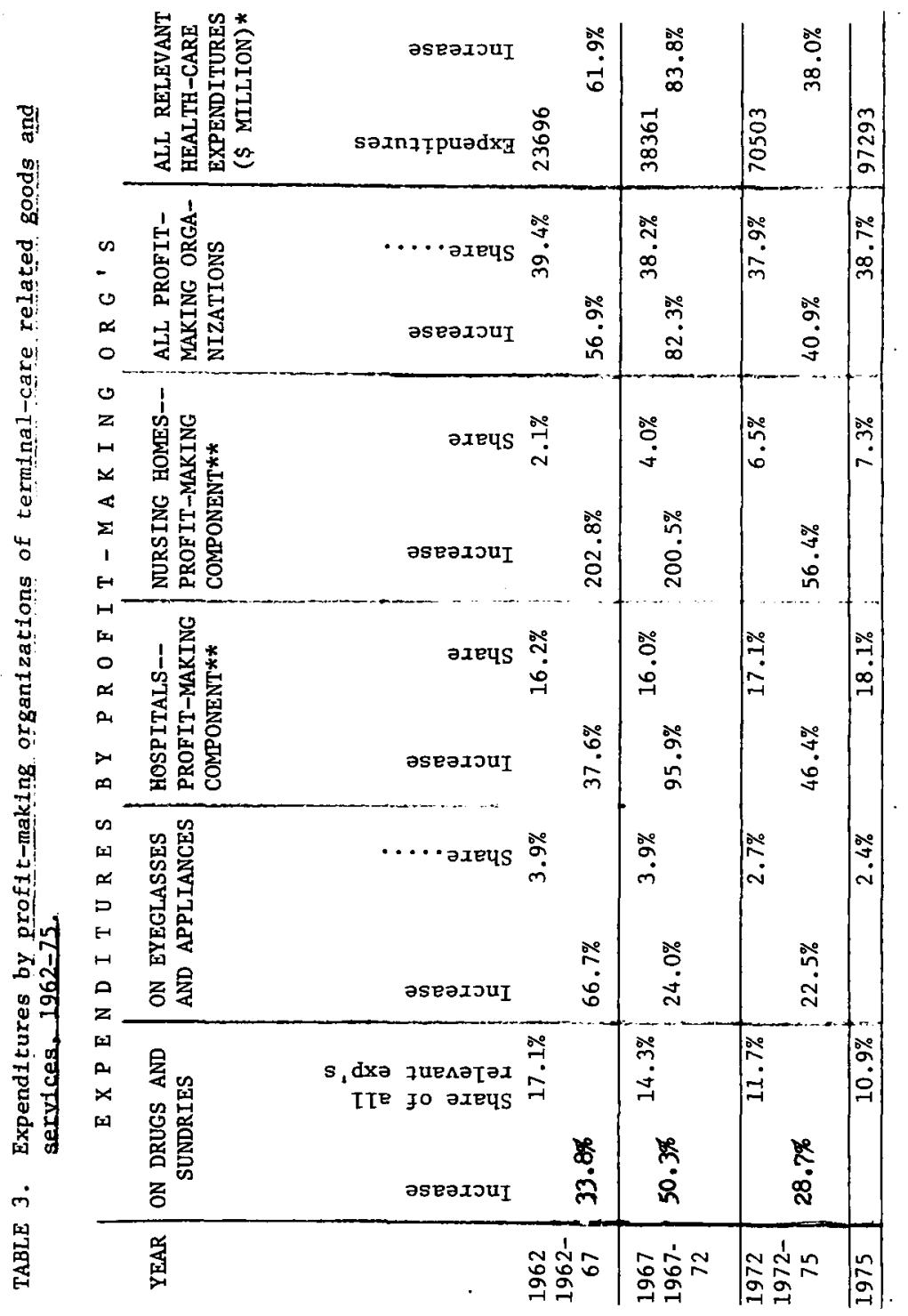


$\underline{\text { Table } 3 \text { cont'd }}$

Source: Stevenson, 1976:2-3

*The sum of: (1) drugs and sundries, (2) eyeglasses and app1iances, (3) hospitals, (4) physicians' services, (5) other professional services, and (6) expenses for prepayment and administration. The expenditures omitted--dentists' services, government public health, research, construction, and other health services-constituted a slowly-declining proportion of all health-care expenditures (17.9\% in 1975).

**The sum of: (1) all expenditures by profit-making hospitals or nursing homes, and (2) for non-profit hospitals or nursing homes, expenditures on food, supplies, drugs, etc.

sales relative to all terminal-care-related expenditures. This trend is consistent with the gradual diffusion of high-technology equipment in hospitals, which we noted in the preceding paragrapha diffusion than can also be used to measure corporate penetration of terminal care. Retuming to Stevenson's data, we also find that in almost all sectors, the most rapid expansion in profitmaking corporations' activity occurred during the years 1967-72. This was after the growth in expressions of ideological concern about the dying in the medical literature. It is interesting that we do not find in the JCD any statement that the medical profession should defend health-care corporations.

An indicator of the growing influence of hospital and other administrators' power over doctors is that the proportion of physicians who are salaried employees has grown somewhat between 1963 and 1973. (McKinlay, unpublished).

Moreover, according to the Marxist position, doctors are increasingly financed-but also regulated-by the state. A rough measure of this trend is the preparation of health care expenditures by the aged that are met by government programs. This proportion suddenly doubled after the introduction of Medicare and Medicaid in 1966, and thereafter remained at about sixty percent. 15 This spurt in governmental activity occurred at just

15. There appears to be no information on the proportion of the elderly's health-care expenditures paid for by the government before 1966. But we know that for all age-groups, the proportion 
the time when professional medical interest in terminal care increased markedly, as shown in Section II. (Cooper and Worthington, 1973a, 1973b; Mueller and Gibson, 1976).

Several of the thematic changes in the JCD that we traced in Section II may be seen as justification of the changes in doctors' typical social relations of production. For instance, there were in the late 1960s and 1970s increasingly frequent calls for cooperation among professionals in terminal-care teams, and members of those teams include such state employees as social workers. Yet in these statements, the doctors' position as the most powerful stratum in health-care delivery institutions is frequent1y justified. ${ }^{16}$

Perhaps too, the growing insistence in the medical literature on honesty towards patients reflects an erosion of physicians' absolute authority over patient care, and also reflects doctors' need to work in somewhat egalitarian teams. For in a setting of team care, patients are probably more likely to learn the truth from non-physician professionals than if the doctor were the undisputed boss. In that event, doctors' prestige is probably better maintained if they are the first professionals to level with patients. Moreover, a doctor who is honest may avoid a malpractice suit. These hypotheses require further research.

\section{CONCLUSIONS}

Summary of Findings

We found in Section II that the number of articles, editorials and letters on the norms of terminal care in the medical literature was larger after 1967 , both in all medical journals

of health-care expenditures paid by the government rose sharply after 1966, from a little over 20 percent between 1950 and 1965, to about 35 percent in the late 1960s (Cooper and Worthington, 1973a).

16. A good example of this ideological stance is found in the widely discussed guidelines proposed at the very prestigious Massachusetts General Hospital in 1976, and published in the New England Journal of Medicine. (Critical Care Committee, 1976). 
and in the JCD. We also found that in the late 'sixties and 'seventies--but not before--doctors were urged to be truthful with dying patients, and to cooperate more closely with other members of the terminal-care team.

In Section III we attempt a preliminary explanation of these findings. We assessed the relative merits of the Parsonian and Marxist perspectives, by examining some readily available timeseries data. These data do not support the Parsonian perspective. But they are consistent with a Marxist perspective, to the extent that simultaneous with the rise in medical interest in terminal care, there was an increase in the medical profession's employment on salary, and in state funding of terminal care. These changes are prima facie consistent with the argument that doctors have become increasingly involved in "largescale, high technology" mode and relations of production.

\section{Suggestions for Further Research}

Further research is clearly needed, not only to enlarge the data-base on the nature of medical ideologies, but also to refine and augment the indicators of possible causes of those ideologies. Specific variables to be studied have been discussed in Section III. Parsonians, Marxists and Freidsonians would all do well to reanalyze ethnographies of medical schools, hospitals and other institutions where health-care is delivered and healthcare workers trained. Since the studies were conducted at a different time, data from them, where comparable, constitute a rough time-series (see for example, Becker et al., 1961; Fox, 1959; Gubrium, 1975; Quint, 1967; Millman, 1976; Sudnow, 1967). For a Parsonian, a useful source of data would be general normative and technical statements in both medical and popular mass media, attitude surveys of both the public and professionals, and community studies (as indicators of popular values and beliefs). For a Marxist, additional information could be found in "political-economy" type histories of relevant technologies, and of major agencies engaged in health-care services, research and funding; 17 in time-series of employment in specialized occupations and work settings; and in the occupational and institutional backgrounds of those publicly expressing different points of view.

17. The studies by Feder (1977) and Strickland (1972) are good examples of recent work on specific agencies. Those by Russe11 (1976) and Stevenson (1976) are good starting points for an analysis of aggregate time-series data. 
It would be of great interest to assess the relative explanatory power of a Marxist and a Freidsonian perspective, since Freidson is very influential among medical sociologists today. A conclusive test of the two perspectives would require a careful examination of which independent variables applied only to one perspective, and which applied to both perspectives. Changes in doctors' work settings are probably relevant to both perspectives, while changes in state activities and in worker or consumer demands can only be used to test a Marxist explanation. 18

Researches such as these will help us understand more clearly not only the changing nature of terminal care, but also the general situation of the whole medical profession. This situation is obviously undergoing major changes, but those changes are still poorly understood.

18. The differences between a Marxist and a Freidsonian explanation are explored in detail in MacDougall and $0 s t$, unpublished. Many of Friedson's concepts and generalizations have strongly influenced Marxist analyses of health care. Freidson's approach also overlaps with Parsons' in Freidson's emphasis on internalized norms as a factor influencing doctors' behavior. However, for Parsons, those norms are general while for Freidson they are situational. 


\section{REFERENCES}

Becker, Howard S., Blanche Geer, Everett Hughes and Anselm Strauss 1961 Boys in White. Chicago: University of Chicago Press.

Blishen, Bernard R.

1969 Doctors and Doctrine: the Ideology of Medical Care in Canada. Toronto: University of Toronto Press.

Conner, J. F., F. B. Devitt and H. J. Switkes

1955 "A hospital unit for the care of the patient with long-term illiness: the intermediate service." Journal of Chronic Diseases 2: 167-179.

Cooper, Barbara S. and Nancy L. Worthington

1975a "Age differences in medical care spending, fiscal year 1972." Social Security Bulletin 36: 3-15.

1973b "National Health Expenditures." Social Security Bulletin 36: 3-19, 40.

Crane, Diana

1975 The Sanctity of Social Life. New York: Russell Sage Foundation.

Critical Care Committee

1976 "Optimum care for hopelessly ill patients." New England Journal of Medicine 295: 364-66.

Dickinson, George E.

1976 "Death Education in U.S. Medical Schools." Journal of Medical Education 51: 134-36.

Feder, Judith M.

1977 Medicare: The Politics of Federal Hospital Insurance. Lexington, Mass.: Heath.

Fox, Renee C.

1959 Experiment Perilous: Physicians and Patients Facing the Unknown. Glencoe, I11.: The Free Press.

Freidson, Eliot

1970a Profession of Medicine. New York: Dodd Mead.

1970b Professional Dominance. Chicago: Aldine. 
1975 Doctoring Together: A Study of Professional Social Control. New York: Elsevier.

Gubrium, Jaber F.

1975 Living and Dying at Murray Manor. New York: St. Martin's

Hinton, John M.

1964 "Editorial: Problems in the Care of the Dying." Journal of Chronic Diseased 17: 203-204.

Illich, Ivan

1976 Medical Nemesis: The Expropriation of Health. New York: Random House.

Iszak, F. C., J. Engel and J. H. Medalie

1973 "Comprehensive Rehabilitation of the Patient with Cancer." Joumal of Chronic Diseases 27: 201-212.

Lasagna, Louis

1969 "Editorial: The Doctor and the Dying Patient." Journal of Chronic Diseases 22: 67-69.

Life-in-Death

1957 "Life-in-Death." New England Journal of Medicine 256: 760-61.

Liston, Edward $\mathrm{H}$.

1973 "Education on Death and Dying: A Survey of American Medical Schools." Journal of Medical Education 48:577-78.

1975 "Education on Death and Dying: A Neglected area in the Medical Curriculum." Omega 6: 193-98.

MacDougall, John and John Ost

Unpub. "Doctors, Death and Dying: Some Ideological Trends."

MacDouga11, John and Marilyn M. Rawnsley

1978 "Power, Professionals and New Ways of Dying." Paper presented at the Annual Meeting of the American Sociological Association.

McKinlay, John B.

1977 "The business of good doctoring or doctoring as good business: Reflections on Freidson's View of the Medical Game." International Journal of Health Services 7: 459-83. 
Unpub. "Towards the Proletarianization of Physicians."

Merton, Robert K., George C. Reeder and Patricia L. Kendall, eds.,

1957 The Student Physician. Cambridge: Harvard University Press.

Millman, Marcia

1976 The Unkindest Cut: Life in the Backrooms of Medicine. New York: Morrow.

Mueller, Marjorie S. and Richard K. Gibson

1976 "Age Differences in Health Care Spending, Fiscal Year 1975." Social Security Bulletin 39: 18-31.

Okun, Donald

1961 "What to Tell Cancer Patients: A Study of Medical Attitudes." Journal of the American Medical Association 175: 1120-28.

Navarro, Vicente

1976 Medicine Under Capitalism. New York: Prodist.

1978 "The Crisis of the Western System of Medicine in Contemporary Capitalism." International Journal of Health Services 8: 179-211.

Newe1l, R. R.

1958 "What Should We Tell the Patient?" Journal of Chronic Diseases 7: 52-57.

Parsons, Talcott

1972 "Definitions of Health and Illness in the Light of American Values." Pp. 107-27 in E. Gartly Jaco, (ed.), Patients, Physicians and Illness, second ed. New York: The Free Press.

Parsons, Talcott, Renee C. Fox and Victor Lidz

1973 "The Gift of Life and Its Reciprocation." Pp. 1-49 in Arien Mack (ed.), Death in American Experience. New York: Schocken.

Parsons, Talcott, and Victor Lidz.

1967 "Death in American Society." Pp. 133-70 in Edwin S. Schneidman (ed.), Essays in Self-Destruction. New York: Science House. 
Quint, Jeanne C.

1967 The Nurse and the Dying Patient. New York: Macmillan.

Russe11, Louise B.

1976 "The Diffusion of New Hospital Technologies in The United States." International Journal of Health Services 6: 557-580.

Rodberg, Leonard and Gelvin Stevenson

1977 "The Health Care Industry in Advanced Capitalism." Review of Radical Political Economics 9: 104-14.

Schulz, Ronald and David Aderman

1976 "How the Medical Staff Copes with Dying Patients." Omega 7: 11-21.

Senescu, Richard A.

1963 "The Development of Emotional Complication in the Patient with Cancer." Journal of Chronic Diseases 16: 825-832.

Stevenson, Gelvin

1976 "Profits in Medicine." Health-PAC Bulletin 72: 2-16.

Strickland, Stephen P.

1972 Politics, Science and Dread Disease: A Short History of United States Kedical Researcy Policy. Cambridge: Harvard University Press.

Sudnow, David

1967 Passing on: The Social Organization of Dying. Englewood Cliffs, N.J., Prentice-Hall.

Theologides, Athanasios

1971 "Editorial: Oncology Service in a Teaching Hospital." Journal of Chronic Diseases 23: 601-604.

Wallace, Anthony F. C.

1956 "Revitalization Movements." American Anthropologist 58.

Waterman, Barbara and Howard Waitzkin

Unpub. "Ideology and Social Control in the Dostor-Patient Relationship." 